\title{
Evaluation by women of painters as a function of their sex and achievement and sex of the judges
}

\author{
AUDREY HONIG \\ Department of Psychology, University of California, Los Angeles, California 90024 \\ and \\ EDWARD C. CARTERETTE \\ Department of Psychology and Brain Research Institute \\ University of California, Los Angeles, California 90024
}

\begin{abstract}
The purpose of the present study was to investigate the conditions under which women devalue female performance. Unfamiliar modern art paintings were presented to 47 women. The sex of the artist, the competitive status of the painting, and the implied sex of the judges who presumably reigned over the competition were dichotomous variables; for each painting five evaluative questions were answered. Women subjects were found to value female work more highly than identical male work when it was only an attempt or entry; however, the reverse was found to be true as the work advanced from entry to winner, regardless of the sex of a competition's judges.
\end{abstract}

Pheterson, Kiesler, and Goldberg (1971) evaluated the alleged performance of artists as a function of their sex, achievement, and personal history. They concluded that women evaluate female entries in a contest less favorably than identical male entries, but female winners were evaluated as equal to identical male winners with respect to talent, emotional impact, and future promise. This suggested to them that women do not devalue another woman once she has attained success.

While we agreed that women do indeed value male work more highly than female work when it is only an attempt or entry, we found it difficult to accept the fact that women unconditionally evaluated a woman's success as equal to that of a man's. We felt that this latter result might be attributed to the fact that the subjects may have assumed that the judges who pronounced this distinction were male, since Pheterson et al. (1971) said nothing about the sexual composition of the organizations accepting entries or judging winners. Since men presumably had already declared these women painters to be superior in artistic talent, by virture of their already having won the contest, then they, the subjects, should also see them as superior. If we assume the existence of this conscious or unconscious motivation, identical accomplishments of male and females may be rated as equal only when they take place in a man's world, thereby attaining a man's stamp of approval, but equal rating may not be given to ac-

This work was part of an independent study project of the first author. Send requests for reprints to Edward C. Carterette, Department of Psychology, University of California, 405 Hilgard Avenue, Los Angeles, California 90024. complishments of women made in a woman's world attested only by a woman's stamp of approval.

The present study was designed to assess this view. Women were asked to judge paintings created by men and women. Some paintings were represented as attempts to accomplish, that is, they were entries in art competitions. Other paintings represented acknowledged accomplishments by having won prizes. In addition, some of the paintings were represented as having been judged by males, other paintings as having been judged by females. The first of three hypotheses ( $\mathrm{H} 1)$ was that women evaluate male attempts to accomplish more highly than those of females, regardless of the sex of the judge who presumably reigned over the competi. tion. The second hypothesis $(\mathrm{H} 2)$ was that women evalu. ate female accomplishments as equal to male accomplish. ments only when those accomplishments attain their special distinction at the hand of male judges. The third hypothesis (H3) was that women evaluate the accomplishments of males more favorably than those of females when those accomplishments attain distinction at the hand of female judges. The third hypothesis flows from our assumption that Pheterson et al. had an uncontrolled source of variability residing in the implicit assumption by their female subjects that competition judges were male. Since it was assumed that female accomplishments require male recognition to be con. sidered equal to male accomplishments $(\mathrm{H} 2)$, accomplish. ments of females should be rated lower than identical accomplishments by males when they have not attained this recognition. This is because they may now be perceived by the subjects to have no greater status than 
the entry paintings and, according to $\mathrm{H} 1$, even in this category, men would be ascribed the more favorable evaluations.

\section{METHOD}

\section{Subjects}

The subjects were 47 women enrolled in a beginning undergraduate psychology class at the University of California, Los Angeles. Service in this experiment was elective and partially satisfied a class requirement. The students were recruited through weekly sign-up sheets, which is according to normal University policy for all such experiments.

\section{Design}

There were four experimental manipulations constituting a $2^{3}$ by 5 design. Eight paintings were presented to small groups of subjects for evaluation. The sex of the artist, the status of the paintings, and the sex of the judges were manipulated, such that for each painting half of the subjects thought it had been created by a male artist, and half thought it had been created by a female artist; half thought it was a prize-winning painting, and half thought it was just an entry in a show; half thought the artist had been judged by male judges, and half thought the artist had been judged by female judges. Each subject participated in each experimental condition, evaluating all eight paintings sequentially. Five different questions, the same five for each painting, were answered. The identity of each painting was counterbalanced among subjects, so that all conditions were represented for each painting.

\section{Procedure}

Subjects were seated in a room equipped with a Kodak carousel $35-\mathrm{mm}$ lantern slide projector and screen. The average distance from subject to viewing surface was $2 \mathrm{~m}$, so that the full-color transparencies subtended an angular size of $28 \mathrm{deg}$ at the eye. Each subject was given a booklet and was told to read the directions: "Slides of eight paintings will be shown in conjunction with brief biographical sketches of the artists. After viewing the slide, turn the page and answer five evaluative questions about the painting. No personal information about your identity, talents, or tastes is required. This is a study of the artistic judgments of college women."

The subjects were then instructed to read the first artist sketch, inspect the projected painting, turn the page and answer the appropriate questions, and then proceed in the same manner for each of the eight slides.

Eight slides of unfamiliar modern art paintings were used. To accompany them, fictitious artist profiles were composed to include the eight experimental conditions. These profiles appeared in the booklets in different orders for the different subjects. Half of the profiles described a female artist and half described a male. Their age, residency, and occupations were briefly described (identical for male and female). For example, "Bob (Barbara) Soulman, born in 1947 in Santa Rosa, California, teaches in a progressive program of adult education. Painting is his (her) hobby and most creative pastime." Crosscutting the sex manipulation, half of the profiles described the painting as a zontest entry (e.g., "She has entered this painting in a museumsponsored young artists' contest"), and half described it as a ecognized winner (e.g., "This painting is the winner of the Annual Los Angeles Color Competition"). In a third manipulaion, half of the profiles described the painting as having been udged by women (e.g., "The judges were Anita Mozley, Ann ischer, Lenore Sherwood, Martha Spelman, and Caroline Jreenwald"), and half described the painting as having been udged my men (e.g., "The judges were Rex Layton, Alan Nalker, David Anderson, Larry Gluck, and Lewis Hine").

After each slide, the subjects turned a booklet page. Five evaluative questions asked the subjects to evaluate the paintings on a scale of $1-5$, with higher ratings representing more favorable evaluations. After every slide, the following questions were posed. Q1: Judging from this painting, how technically competent would you judge Mr. (Ms.) _to be? Q2: How creative would you judge Mr. (Ms.) to be? Q3: What rating would you give to Mr. (Ms.) for the overall quality and content of his (her) painting? Q4: What emotional impact has Mr. (Ms.) __ instilled in his (her) painting? Q5: Judging from this painting, what prediction would you make for the artistic future of Mr. (Ms.)

After all eight slides had been shown, subjects were asked to state briefly what they thought was the purpose of the experiment, in order to see whether or not the subjects verbalized any central features of the purpose or design of the experiment. They did not. The study was then explained, and the subjects were asked not to discuss it.

\section{RESULTS AND DISCUSSION}

The results were analyzed using a repeated-measures analysis of variance. ${ }^{1}$ Sex of the artist (SA), sex of the judges (SJ), competition status of the painting (CS), and question $(\mathrm{Q})$, were the experimental conditions, with subjects as an additional factor.

There was a significant main effect due to the variable $Q[F(4,184)=16.01, p<.001]$. None of SA, SJ, or CS was significant at the .06 level of confidence, though interactions among SA, CS, and Q were [CSXQ: $F(1,46)=2.30, p<.06 ; \operatorname{SAXCSXQ:~} F(4,184)=2.52$, $\mathrm{p}<.02]$.

A separate analysis by questions showed that Q3, on overall painting quality and content, was largely responsible for the main effect of $Q$, with a significant interaction of the artist's sex and competition status of the painting [SAXCS: $F(1,46)=3.86, p<.055]$.

Females were rated higher when their paintings were entered in a competition than when winners in a competition (see Table 1). Males tended to be given higher evaluations when their paintings were winners than when merely entries.

All other questions, with the exception of Q4 on emotional impact, produced results paralleling those of Q3, though none reached statistical significance at $\mathrm{p}<.10$ in the separate analysis. An analysis of Q4 on emotional impact showed that both male and female enterers were rated the same and more highly than winners, but female winners were rated higher than male winners.

None of the three hypotheses was supported by the data. We cannot reject the null hypothesis (related to H1) that women evaluate male attempts to accomplish

Table 1

Mean Quality and Content Ratings of Male and Female Artists With Winning or Entered Paintings

\begin{tabular}{lcc}
\hline Status of & \multicolumn{2}{c}{ Sex of Artist } \\
Painting & Male & Female \\
\hline Winner & 3.49 & 3.41 \\
Entered & 3.32 & 3.56 \\
\hline
\end{tabular}


equally with female attempts to accomplish, no matter what the sex of the judges. There is no evidence that women evaluate the accomplishments of female artists as highly as those of men only if the judges are men $(\mathrm{H} 2)$. And there is no evidence for $\mathrm{H} 3$, that when distinction is attained under female judges, women will rate the accomplishments of male artists higher than those of female artists.

However, the data do support the assumption that women value female work more highly than male work when it is only an attempt or entry, but that male work is more highly valued when that work advances from entry to winner, regardless of the sex of the judge who pronounces the distinction. Statistically, this is shown by (1) the absence of a main effect or any interaction involving the sex of the judges (SJ) and by (2) the interaction of artist's sex and the competition status of the paintings (SAXCS).

In summary, it appears that our results contradict our hypotheses. In addition, they do not support the Pheterson et al. (1977) contention that women evaluate female enterers in a contest less favorably than identical male enterers, but female winners equally to identical male winners. In fact, it seems likely that our results and those of Pheterson et al. may not be too disparate since their positive findings were only marginally significant. The implications of these findings are that an artist of neither sex can expect a completely unbiased evaluation of that artist's work. The direction that this bias takes, however, is dependent on the interaction of the individual's sex and status. Women subjects were biased against female success but not female attempts at success; conversely, women subjects were biased against male attempts at success but not male success.

Our intuition is still in conflict with the experimentally revealed truth. We would wish it to be true that women evaluate women's artistic successes, or attempts to succeed, equally with those of men. We would also wish it to be true that the verdict of an all-female jury is accepted by women as equal in status to the verdict of an all-male jury. But, we doubt this truth, which takes the form of failing to reject a set of null hypotheses. More convincing experimental results might be obtained by greater removal from the laboratory-for example, by use of the paintings themselves, by use of simulated or real judges, and by use of photographs or cinemas of the artists. However, before going to these lengths, we are led by an examination of our questions to believe that responses to the questions were constrained to lie in a narrow range. This was due to the ratings 1,3 , and 5 being defined as below average, average, and above average, respectively, with the ratings 2 and 4 falling in natural sequence, though without specific written designations of their own. Details of the variance analy sis show the range of mean ratings to be \pm .72 and the range of standard deviations to be \pm .43 .

One other factor should be considered in any further analysis. Undergraduate women at UCLA may have a bias for imbuing their public responses with an attitude toward the potentiality of an artist which is unbiased by the sexual condition.

\section{REFERENCE}

Pheterson, G. I., Kiesler, S. B., \& Goldberg, P. A. Evaluation of the performance of women as a function of their sex, achievement, and personal history. Journal of Personality and Social Psychology. 1971, 19, 114-118.

\section{NOTE}

1. BMDP2V, Analysis of variance and covariance including repeated measures. Biomedical Computer Programs. Berkeley and Los Angeles: University of California Press, 1975.

(Received for publication February 9, 1978.) 